\title{
Micrometeorological measurement of hexachlorobenzene and polychlorinated biphenyl compound air-water gas exchange in Lake Superior and comparison to model predictions
}

\author{
M. D. Rowe ${ }^{1, *}$ and J. A. Perlinger ${ }^{1}$ \\ ${ }^{1}$ Civil \& Environmental Engineering, Michigan Technological University, Houghton, MI, USA \\ * now at: US Environmental Protection Agency, Grosse Ile, MI, USA \\ Correspondence to: J. A. Perlinger (jperl@mtu.edu)
}

Received: 21 December 2011 - Published in Atmos. Chem. Phys. Discuss.: 11 January 2012

Revised: 12 April 2012 - Accepted: 29 April 2012 - Published: 24 May 2012

\begin{abstract}
Air-water exchange fluxes of persistent, bioaccumulative and toxic (PBT) substances are frequently estimated using the Whitman two-film (W2F) method, but micrometeorological flux measurements of these compounds over water are rarely attempted. We measured air-water exchange fluxes of hexachlorobenzene (HCB) and polychlorinated biphenyls (PCBs) on 14 July 2006 in Lake Superior using the modified Bowen ratio (MBR) method. Measured fluxes were compared to estimates using the W2F method, and to estimates from an Internal Boundary Layer Transport and Exchange (IBLTE) model that implements the NOAA COARE bulk flux algorithm and gas transfer model. We reveal an inaccuracy in the estimate of water vapor transfer velocity that is commonly used with the W2F method for PBT flux estimation, and demonstrate the effect of use of an improved estimation method. Flux measurements were conducted at three stations with increasing fetch in offshore flow $(15,30$, and $60 \mathrm{~km})$ in southeastern Lake Superior. This sampling strategy enabled comparison of measured and predicted flux, as well as modification in near-surface atmospheric concentration with fetch, using the IBLTE model. Fluxes estimated using the $\mathrm{W} 2 \mathrm{~F}$ model were compared to fluxes measured by MBR. In five of seven cases in which the MBR flux was significantly greater than zero, concentration increased with fetch at 1-m height, which is qualitatively consistent with the measured volatilization flux. As far as we are aware, these are the first reported ship-based micrometeorological air-water exchange flux measurements of PCBs.
\end{abstract}

\section{Introduction}

Contamination of ecosystems by atmospheric deposition of persisent, bioaccumulative and toxic (PBT) substances is a continuing concern for human and ecosystem health. Currently $43 \%$ of total lake acreage and $39 \%$ of total river miles in the United States are under fish consumption advisories, including $100 \%$ of the Great Lakes and connecting waters. Seventy nine percent of US coastal waters are under advisory, including nearly all of the East Coast and Gulf Coast. Mercury, dioxins, polychlorinated biphenyls (PCBs), DDT, and chlordane are responsible for most advisories (US EPA, 2008). For large bodies of water, gaseous exchange with the atmosphere is a dominant process in the mass balance for relatively volatile and water-insoluble chemicals such as PCBs and mercury (Jeremiason et al., 1994; Rowe et al., 2008), and an important contributing process for less volatile or more water soluble compounds such as polybrominated diphenyl ethers (Rowe et al., 2008) and some current use pesticides (Harman-Fetcho et al., 2000). Quantification of the rate of gaseous exchange with the atmosphere is needed to understand and predict the behavior of toxics in surface waters.

Gaseous exchange fluxes of PBTs are usually estimated from measurements of atmospheric and aqueous concentration using the Whitman two-film (W2F) model (e.g., Blanchard et al., 2008) but measurement of fluxes using micrometeorological methods are rarely attempted. In one recent example, Sandy et al. (2012) measured PCB air-water exchange fluxes using an aerodynamic gradient method from a pier in a PCB-contaminated area of the Hudson River estuary. W2F flux estimates are subject to uncertainty in concentration

Published by Copernicus Publications on behalf of the European Geosciences Union. 
measurements, temperature-dependent Henry's law constant, and mass transfer velocity parameterizations. Micrometeorological methods, such as the modified Bowen ratio (MBR) method (Perlinger et al., 2005; Wesely et al., 1987), can be used to measure the flux more directly, and thus provide a means to evaluate gas transfer parameterizations. Recent field studies of PBT air-water exchange in oceanic waters have revealed the difficulty in estimating Henry's law constant for these compounds (Gioia et al., 2010), and the need for improved methods to make direct flux measurements (Wong et al., 2011). Uncertainties in MBR flux measurements are dominated by the chemical concentration measurement precision, and also depend on atmospheric variables (Rowe et al., 2011b), but knowledge of Henry's law constant and surface mass transfer parameterizations is not required.

We use a novel chemical concentration measurement method, and evaluate whether flux measurement uncertainty is sufficiently low to critically evaluate gas transfer parameterizations for these compounds using the MBR method. MBR flux measurements are reported with error estimates for HCB and several PCB congeners at three stations in eastern Lake Superior with increasing fetch in offshore flow. We compare measured fluxes to estimates from the W2F model and a more complex Internal Boundary Layer Transport Exchange (IBLTE) model (Rowe et al., 2011a) that implements the NOAA COARE bulk flux algorithm and gas transfer model. The COARE gas transfer model (Fairall et al., 2000) differs from the W2F model in that it accounts for effects of atmospheric stability on fluxes in the constant-flux surface layer. In the coastal zone during offshore flow, conditions of horizontal homogeneity may be compromised to the extent that on-shore gas mixing ratios (typically what is used in W2F PBT flux estimates) are unrepresentative of over-water mixing ratios. Also, the constant flux layer may occur in the atmospheric surface layer below the height of measurement, in particular under stable atmospheric conditions, which frequently occur in the Laurentian Great Lakes when warm air is advected over cold water (e.g., Rowe et al., 2011a). This situation will cause measured flux to be unrepresentative of the surface flux. Here, the COARE gas transfer model is applied within the IBLTE model to estimate the modification of PBT gaseous concentration, surface fluxes, and near-surface vertical gradients with fetch.

\section{Model description and experimental methods}

\subsection{Internal boundary layer transport and exchange (IBLTE) model}

The IBLTE model (Rowe et al., 2011a) takes a Lagrangian perspective, following an air mass as it flows from the coast with increasing fetch over water. The height to which the atmosphere is modified by interaction with the water surface is defined as the internal boundary layer height $\left(h_{\mathrm{ibl}}\right)$. A mass balance is conducted by vertically integrating the modification in mixing ratio from the surface to $h_{\mathrm{ibl}}$, and this quantity is assumed equal to the air-water exchange flux at the surface integrated over the fetch. Gas transfer velocities at the surface are given by the COARE gas transfer model. The IBLTE model assumes a well-mixed layer is advected from land, neglects directional wind shear, and subsidence. These effects may be important in some cases.

The IBLTE model is intended to be used with inputs that are available from surface measurements: wind speed, air temperature, humidity, and mixing ratio incident upon the coast, as well as water temperature and aqueous concentration. The model can be used to predict the variation in several quantities with fetch within the surface layer, defined as $0.1 \times h_{\mathrm{ibl}}$ : (1) modification in potential temperature and gas mixing ratio from the over-land values, (2) surface fluxes of sensible heat, latent heat, and any trace gas, and (3) vertical gradients in potential temperature and mixing ratio.

\subsection{Parameterization of air-water gas exchange flux}

Air-water exchange flux is commonly estimated using a bulk relationship:

$F=k_{\mathrm{ol}}\left(C_{\mathrm{w}}-\frac{C_{\mathrm{a}}}{K_{\mathrm{aw}}}\right)$

where $F$ is the flux, $C_{\mathrm{w}}$ and $C_{\mathrm{a}}$ are the concentration of the chemical of interest in water and air, respectively, and $K_{\text {aw }}$ is the dimensionless Henry's Law constant at the water surface temperature. Equilibrium solubility (dimensionless Henry's Law constant) is expressed in the literature with various conventions:

$$
\frac{C_{\mathrm{a}}}{C_{\mathrm{w}}}=\frac{H}{R T_{\mathrm{a}}}=K_{\mathrm{aw}}=\frac{1}{\alpha}
$$

where $H$ is Henry's Law constant (units of, e.g., $\mathrm{L} \mathrm{bar} \mathrm{mol}^{-1}$ ) at the water surface temperature, $T_{\mathrm{a}}$ is the reference temperature for the gaseous concentration, and $R$ is the gas constant. In oceanic and atmospheric sciences, it is common to use the dimensionless solubility, $\alpha$ (for example, Fairall et al., 2000), while $H$ and $K_{\text {aw }}$ are common in environmental organic chemistry. The overall mass transfer coefficient, $k_{\mathrm{ol}}$, is a function of air-side, $k_{\mathrm{a}}$, and water-side, $k_{\mathrm{w}}$, transfer velocities, and solubility.

$\frac{1}{k_{\mathrm{ol}}}=\left(\frac{1}{k_{\mathrm{w}}}+\frac{1}{K_{\mathrm{aw}} k_{\mathrm{a}}}\right)$

The air-side and water-side transfer velocities, $k_{\mathrm{a}, \mathrm{w}}$, are a function of the molecular diffusivity of the chemical of interest in air or water, $D$, the height and stability-dependent turbulent diffusivity, $K(z)$, and the reference height (or depth) at 
which the concentrations are measured (Fairall et al., 2000):

$$
\frac{\Delta C}{F}=\int_{0}^{z_{r}} \frac{d z}{D+K(z)}=\frac{1}{k_{\mathrm{a}, \mathrm{w}}}
$$

where $\Delta C$ is the concentration difference between the vanishingly-thin atmospheric layer in direct contact with the surface and the reference height. Turbulent diffusivity increases approximately linearly with distance away from the surface, thus most of the transfer resistance given by the integral term in Eq. (4) for the air-side occurs within the first $0.5 \mathrm{~mm}$ above the air-water interface in which molecular diffusion controls transport (Fairall et al., 2000). In the W2F parameterization, all transfer resistance is assumed to occur within the air-side and water-side molecular sublayers, the turbulent and molecular diffusion contributions are lumped together in empirical parameterizations of water vapor and carbon dioxide transfer velocity as a function of 10-m wind speed, gradients above and below the surfaces are neglected, and measurement height is not explicitly represented. Effects of atmospheric stability are not accounted for in the W2F model. In the COARE gas transfer model, height-dependent transfer velocity is parameterized as a function of the airside and water-side Schmidt numbers and turbulence scaling parameters. Effects of atmospheric stability and water-side buoyancy are included, and disruption of the molecular sublayers by breaking bubbles at high wind speeds is accounted for.

\subsection{Whitman two-film (W2F) model transfer velocity}

In this section, we describe a commonly-used parameterization for PBT organic compound transfer velocity, and point out that it contains an inaccurate expression for the water vapor transfer velocity. The following simplified W2F transfer velocity parameterizations are used by the Integrated Atmospheric Deposition Network Project to estimate PBT gas transfer in the US Laurentian Great Lakes (Galarneau et al., 2000; Hornbuckle et al., 1994).

$k_{\mathrm{w}}=v_{\mathrm{CO}_{2}}\left(\left(\frac{V_{\mathrm{PBT}}}{V_{\mathrm{CO}_{2}}}\right)^{0.6}\right)^{-n}$

$k_{\mathrm{a}}=v_{\mathrm{w}}\left(\frac{D_{\mathrm{PBT}}}{D_{\mathrm{w}}}\right)^{0.61}$

where $n=2 / 3$ for $U_{10}$, the stream-wise horizontal wind speed at $10 \mathrm{~m}$ over the water surface in units of $\mathrm{m} \mathrm{s}^{-1}$, less than 3.6, and $n=0.5$ for $U_{10} \geq 3.6 \mathrm{~m} \mathrm{~s}^{-1}$ (Bidleman and McConnell, $1995)$, and $V_{\mathrm{PBT}}$ and $V_{\mathrm{CO}_{2}}$ are the molar volumes for PBT and carbon dioxide, respectively. In these equations, $k_{\mathrm{a}}$ and $k_{\mathrm{w}}$ are related to the transfer velocity of a reference gas by the ratio of Schmidt numbers. Reference gases are waterside transfer resistance limited $\left(\mathrm{CO}_{2}\right)$ or air-side transfer resistance limited (water vapor). In Eq. (5), diffusivity is estimated using the Wilke Chang method, resulting in the ratio of molar volumes raised to the power 0.6. A molar volume of $29.6 \mathrm{~cm}^{3} \mathrm{~mol}^{-1}$ for $\mathrm{CO}_{2}$ is used. In Eq. (6), the method of Fuller et al. (1966) is used to calculate the gas-phase diffusivities. These diffusivity estimation methods are described elsewhere (Schwarzenbach et al., 2003).

Hornbuckle et al. (1994) used the following expressions to estimate transfer velocity for the reference gases water vapor and carbon dioxide:

$v_{\mathrm{w}}\left(\mathrm{cm} \mathrm{s}^{-1}\right)=0.2 U_{10}+0.3$

$v_{\mathrm{CO}_{2}}\left(\mathrm{cmh}^{-1}\right)=0.45 U_{10}^{1.65}$

Equation (7) was originally published in the 1993 edition of the Schwarzenbach et al. (2003) environmental organic chemistry text. Equation (8) is from Wanninkhof et al. (1991). These expressions have become almost universally adopted to estimate air-water exchange of PBT organic compounds (for example, Galarneau et al., 2000; Gioia et al., 2008; Dachs et al., 2002; Rowe et al., 2007; Totten et al., 2001; Yan et al., 2008; Zhang et al., 2008). An earlier expression is sometimes used (e.g., Meng et al., 2008; Wong et al., 2011) that gives $k_{\mathrm{a}}$ as a function of $U_{10}$ and Schmidt number, derived from measurements of volatilization of organic compounds from a wind-wave tank (Mackay and Yeun, 1983).

A factor of two discrepancy exists between Eq. (7) and ship-based micrometeorological measurements of water vapor transfer velocity. Equation (7) was proposed as a function that reasonably approximated a set of $v_{\mathrm{w}}$ measurements collected from six literature sources, after adjusting them to a common 10-m reference height. The data set included wind tunnel, evaporation pan, and field measurements at reference heights of $0.075,0.1,2,6$, and $10 \mathrm{~m}$. Equation (7) gives $v_{\mathrm{w}}$ of $0.013 \mathrm{~m} \mathrm{~s}^{-1}$ at $U_{10}=5 \mathrm{~m} \mathrm{~s}^{-1}$, or a $10-\mathrm{m}$ neutral water vapor transfer coefficient, $C_{e 10 n} \equiv v_{\mathrm{w}} / U_{10}$, of $2.6 \times 10^{-3}$. In contrast, Fairall et al. (2003) present data over the $U_{10}$ range from 1 to $19 \mathrm{~m} \mathrm{~s}^{-1}$ and cite several supporting data sources, indicating that $C_{e 10 n}=1.15 \times 10^{-3}$ within $5.3 \%$, which differs from the value implied by Eq. (7) by approximately a factor of two. Thus, the transfer velocity parameterization described by Eqs. (5) to (8) could be improved by adopting the more widely accepted value for $C_{e 10 n}$. More recent expressions for the $\mathrm{CO}_{2}$ transfer velocity are also available (e.g., Ho et al., 2006). For the PCBs and HCB considered here, $k_{\mathrm{ol}}$ estimated by W2F with $C_{e 10 n}=1.15 \times 10^{-3}$ in place of Eq. (7) gives a $10-20 \%$ reduction in estimated $k_{\mathrm{ol}}$; the difference would be greater for air-side transfer resistance limited compounds.

Even if appropriate expressions are used for Eqs. (7) and (8), the W2F method neglects the influence of atmospheric stability on $k_{\mathrm{a}}$, buoyancy effects on $k_{\mathrm{w}}$, and does not explicitly account for film disruption by breaking bubbles at higher wind speeds or surface films. The first three phenomena are explicitly parameterized in the COARE gas transfer model that is applied within the IBLTE model. 
Table 1. Conditions at the three sampling stations in eastern Lake Superior on 14 July 2006, and average temperature at the upper (8.5 m) and lower $(1 \mathrm{~m})$ platforms.

\begin{tabular}{llllllllll}
\hline $\begin{array}{l}\text { Start time, } \\
\text { EDT }\end{array}$ & $\begin{array}{l}\text { Finish time, } \\
\text { EDT }\end{array}$ & Lat. & Lon. & $\begin{array}{l}\text { Fetch, } \\
\mathrm{km}\end{array}$ & $\begin{array}{l}\text { Wind speed, } \\
\mathrm{m} \mathrm{s}^{-1}\end{array}$ & $\begin{array}{l}T_{\mathrm{w}}, \\
{ }^{\circ} \mathrm{C}\end{array}$ & $\begin{array}{l}T_{\mathrm{a}}, \\
{ }^{\circ} \mathrm{C} \text { lower }\end{array}$ & $\begin{array}{l}T_{\mathrm{a}}, \\
{ }^{\circ} \mathrm{C} \text { upper }\end{array}$ & $\begin{array}{l}\text { Sensible heat flux, } \\
\mathrm{W} \mathrm{m}^{-2}\end{array}$ \\
\hline 0620 & 0750 & 46.8571 & 85.3450 & 15.7 & 3.5 & 19.3 & 19.4 & 19.5 & -1.5 \\
0922 & 1052 & 46.9974 & 85.3245 & 28.3 & 3.4 & 16.9 & 16.7 & 18.3 & -5.2 \\
1318 & 1448 & 47.2783 & 85.3099 & 58.8 & 4.6 & 15.5 & 16.1 & 17.8 & -9.0 \\
\hline
\end{tabular}

\subsection{Use of the COARE gas transfer model with PBT organic compounds}

We applied the COARE gas transfer model to obtain stability-dependent PBT gas transfer velocities. COARE has been applied to $\mathrm{CO}_{2}$ and dimethylsulfide (DMS), but has not been previously applied to PBT organic compounds. For example, the COARE gas transfer model was calibrated to over-water $\mathrm{EC} \mathrm{CO}_{2}$ flux measurements (Fairall et al., 2003; Hare et al., 2004). The model calibrated to the GasEx 2001 $\mathrm{CO}_{2}$ data was found to adequately describe DMS fluxes measured by EC (Blomquist et al., 2006). In a more recent study (Marandino et al., 2009), the COARE gas transfer model was shown to give $k_{\mathrm{ol}}$ at the low end of values measured for DMS by EC, which displayed considerable variability.

The COARE 3.0 bulk algorithm and COARE 3.0 DMS gas transfer model (Blomquist et al., 2006) were obtained as MATLAB scripts. The equation for $k_{\mathrm{a}}$ in COARE 3.0 DMS was modified as in Eq. (9):

$k_{\mathrm{a}}=\frac{u_{*}}{h_{\mathrm{a}} S c_{\mathrm{a}}^{1 / 2}+\kappa^{-1}\left[\ln \left(\frac{z_{\mathrm{ra}}}{z_{0}}\right)-\Psi_{H}\left(\frac{z_{\mathrm{ra}}}{L}\right)\right]-5+\frac{\ln \left(S c_{\mathrm{a}}\right)}{2 \kappa}}$

where $u_{*}$ is the air-side friction velocity, $h_{\mathrm{a}}$ is the coefficient of the air-side molecular sublayer estimated as 13.3 neglecting sublayer buoyancy effects, $S c_{\mathrm{a}}$ is the Schmidt number of the compound of interest in air, $\kappa=0.4$ is the von Kármán constant, $z_{\mathrm{ra}}$ is the reference height above the water surface, $z_{o}$ is roughness length, $L$ is Obukhov length, and $\Psi_{H}\left(\frac{z_{\text {ra }}}{L}\right)$ is the Monin-Obukhov similarity theory integral profile function for potential temperature, used to describe the stability and height-dependent turbulent diffusivity for sensible heat and gas mixing ratio (Fairall et al., 2000; Blomquist et al., 2006). The second term in the denominator of Eq. (9) replaces $C d^{-1 / 2}$ in Eq. (5a) of Blomquist et al. (2006) because stability was neglected in the original derivation (C. W. Fairall, personal communication, 16 May 2007). Four compound-specific properties are needed to apply the COARE gas transfer model to PBTs: watertemperature dependent Henry's Law slope $A$ and intercept $B$, as in:

$\log (H)=\frac{A}{T_{\mathrm{w}}}+B$

molecular mass, and Le Bas molar volume. Temperature dependence expressions for Henry's law constant for HCB from Jantunen and Bidleman (2006), for PCBs from Bamford et al. (2002) and for PBDEs from Cetin and Odabasi (2005) were used. Solubility was then calculated from the temperature-corrected $H$-value using Eq. (2). Compound diffusivity in air was calculated using the Fuller (1966) equation, and in water using the Hayduk Laudie Equation, as in the text by Schwarzenbach et al. (2003). Schmidt numbers in air and water were calculated using temperature dependent expressions for viscosity obtained from the COARE 3.0 algorithm (air) and the text by White (1999) (water).

\subsection{Experimental methods}

\subsubsection{Site description}

Modified Bowen ratio flux measurements were conducted at three stations with increasing fetch under offshore flow conditions in eastern Lake Superior on 14 July 2006 on board the US EPA R/V Lake Guardian. Station locations, sampling times, and meteorological variables are reported in Table 1. The station locations are shown in Fig. 1 along with NOAA HYSPLIT model air parcel backward trajectories and water surface temperature from the NOAA GLSEA data product.

\subsubsection{Modified Bowen ratio (MBR) flux measurements}

Equipment and methods described in detail by Perlinger et al. (2005) were used, except averaging time was ca. $1.5 \mathrm{~h}$. Measurements were made at upper and lower platforms located at $8.5 \mathrm{~m}$ and $1 \mathrm{~m}$ above the water surface, respectively. PBT concentration and air temperature (aspirated thermocouple) were measured at both platforms. At the upper platform, sensible heat flux was measured by EC using the sonic anemometer temperature along with six-axis ship motion, and mean temperature and humidity were measured using a separate aspirated probe. EC measurements were corrected for ship motion using methods of Edson et al. (1998) and computer code provided by NOAA/ESRL. Motion corrections were small. Examination of flux cospectra revealed no low-frequency disturbances. A transfer velocity, $k_{a 12}$, over the layer of atmosphere between the two platforms is obtained for sensible heat by combining the difference in 


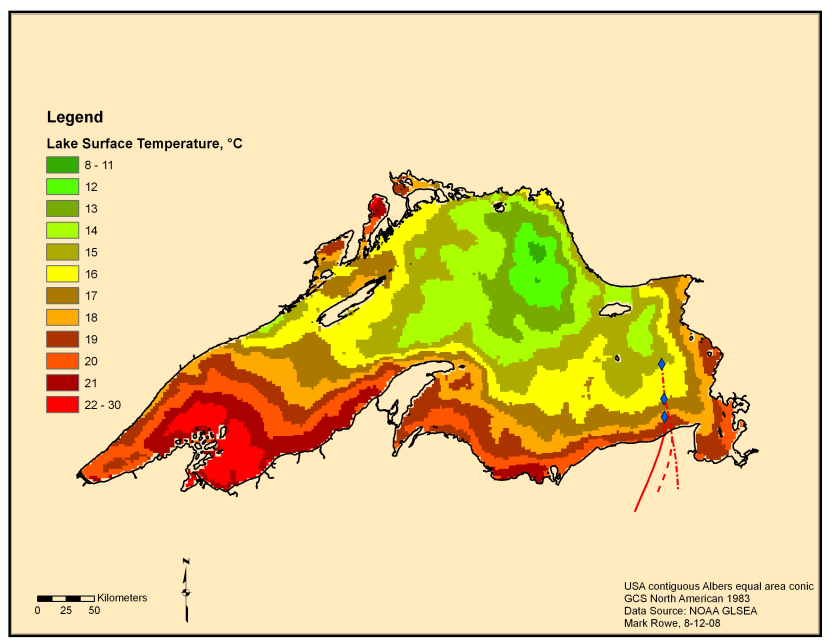

Fig. 1. A map of Lake Superior showing the station locations (diamonds), NOAA HYSPLIT air parcel backward trajectories (lines), and NOAA GLSEA lake surface temperatures for 14 July 2006.

potential temperature between the two platforms, $\Delta \theta$, with the kinematic sensible heat flux, $\overline{w^{\prime} \theta^{\prime}}$ :

$k_{a 12}=\frac{\overline{w^{\prime} \theta^{\prime}}}{\Delta \theta}$

This transfer velocity is assumed to apply to all conserved scalar variables (a transport mechanism of turbulent diffusion by small eddies is assumed), and the flux, $F$, is calculated from the difference in concentration, $\Delta \mathrm{C}_{\mathrm{a}}$, between the two platforms:

$F=k_{a 12} \Delta C_{\mathrm{a}}=\frac{\overline{w^{\prime} \theta^{\prime}}}{\Delta \theta} \Delta C_{\mathrm{a}}$

Mixing ratio is the conserved variable for gases. However, because pressure variation with height is negligible over the first $10 \mathrm{~m}$ of the atmosphere, concentration in $\mathrm{pg} \mathrm{m}^{-3}$, referenced to a standard temperature and pressure $\left(25^{\circ} \mathrm{C}, 1 \mathrm{~atm}\right)$, may be used directly in this calculation to obtain a flux in $\mathrm{pg} \mathrm{m}^{-2} \mathrm{~s}^{-1}$.

Flux measurements should be conducted within the constant flux surface layer if the measured flux is to be considered representative of the surface flux. A constant flux surface layer exists under conditions of stationarity, horizontal homogeneity, and a lack of sources or sinks between the measurement height and the surface. In the case of offshore flow in the coastal zone, a gradient in the stream-wise direction may exist, in which case flux will vary with height above the surface. However, if measurement height is sufficiently low, the flux at the measurement platform approximates the surface flux. For example, Fairall et al. (2006, Fig. 9) found that bulk transfer coefficients calculated from fluxes measured at 18-m height matched those of the COARE Algorithm when the IBL height was greater than $\sim 180 \mathrm{~m}$. Thus, an approach to test whether measured fluxes are expected to represent surface fluxes is to compare fluxes of sensible heat, latent heat, or momentum to those given by the COARE algorithm, which has been calibrated and verified against many hours of open ocean flux measurements where horizontal homogeneity was assured.

\subsubsection{Chemical analysis}

Gaseous concentration of PBTs was measured using lowflow (13 $\mathrm{L} \mathrm{min}^{-1}$ ) denuder samplers consisting of $289 \mathrm{sec}-$ tions of capillary gas chromatograph (GC) columns packed into a deactivated stainless steel tube. Details of design, construction, and application of the low-flow denuders are given elsewhere (Tobias et al., 2007; Rowe and Perlinger, 2009a). Sample extraction, cleanup, GC analysis, and quality assurance procedures are described in detail elsewhere (Rowe and Perlinger, 2009a). Analytes included hexachlorobenzene, 144 PCB congeners, and PBDEs 47 and 99. Only those analytes that frequently exceeded the method detection limit are discussed subsequently. A sample was collected at the upper and lower platform at each of the three stations. In addition, a sample was collected on deck in the ship's bow during $70 \mathrm{~min}$. in transit from 15 - to $30-\mathrm{km}$ stations plus $34 \mathrm{~min}$. in transit from 30- to $60-\mathrm{km}$ stations, and an additional sample during $35 \mathrm{~min}$. in transit from 30 - to $60-\mathrm{km}$ stations plus $53 \mathrm{~min}$. in transit beyond the $60-\mathrm{km}$ station. A field blank was transported and stored with the samples, and opened inside the upper sampler housing during one sample collection period with no air flow through the denuder. A trip blank was transported and stored with the samples.

The denuders were capped with air-tight fittings and stored 19 months at $4{ }^{\circ} \mathrm{C}$ prior to extraction and analysis. A pair of blank denuders stored four years in the same refrigerator and analyzed along with the samples had $100 \pm 10 \%$ recovery of surrogate standards PCB 14, 65, and 166, and HCB mass less than $20 \%$ of these samples, providing evidence that surrogate recoveries and blank levels were not affected by storage. A calibrated and validated breakthrough model (Rowe and Perlinger, 2009b) predicted $<10 \%$ breakthrough for the least retained analytes reported here (HCB and PCB 8) for sampling time up to $3 \mathrm{hr}$ at the maximum sampling temperature observed $\left(19.5^{\circ} \mathrm{C}\right)$, providing evidence that analytes were not lost to breakthrough in the $1.5 \mathrm{hr}$ sample collection times used here ( $0 \%$ breakthrough predicted). Breakthrough was also not predicted for any of the surrogate standards, although low recovery was observed for some surrogate standards in the samples. Surrogate standards PCB 14, 65 , and 166 , spiked into denuders prior to sampling, were recovered $28 \pm 4 \%, 75 \pm 4 \%$, and $96 \pm 6 \%$ (median \pm range), respectively. Because the method is well characterized and validated (Rowe and Perlinger, 2009a), breakthrough of analytes during sampling was not predicted, and evidence exists that samples were not affected by storage, it is likely that low 
recovery of surrogate PCB 14 occurred because of the hotspike process for introduction of surrogate standards prior to sample collection. Although PCB 14 has similar retention characteristics to HCB in diffusion denuders, the hotspike procedure heats the denuder inlet and deposits surrogates some distance into denuder capillaries, reducing their effective breakthrough volumes. The lowest PCB 14 recoveries occurred in denuders with greater sample volume, supporting the hypothesis that low PCB 14 recovery was caused by breakthrough. Analyte mass in blanks was $<20 \%$ of analyte mass in samples $(<6 \%$ for HCB). Analyte mass was greater than the method detection limit (Rowe and Perlinger, 2009a) for all reported concentrations, except in three cases as indicated in Table 4. Reported concentrations were blank subtracted, but not adjusted for surrogate recovery.

Propagation of error analysis applied to the MBR flux measurement, Eq. (12), yields the following expression for relative error on the flux:

$\frac{\delta F}{F}=\sqrt{\left(\frac{1}{\rho C_{p} \overline{w^{\prime} \theta^{\prime}}}\right)^{2}+(0.2)^{2}+\left(\frac{\sqrt{2} \cdot \delta C_{\mathrm{a}}}{\Delta C_{\mathrm{a}}}\right)^{2}+\left(\frac{\sqrt{2} \cdot 0.1}{\Delta \theta}\right)^{2}}$

where the error in the sensible heat flux measurement is divided into a mean bias of $1 \mathrm{~W} \mathrm{~m}^{-2}$ and a relative error of $20 \%$ (Fairall et al., 2003), $\rho$ is the density of moist air $\left(\mathrm{kg} \mathrm{m}^{-3}\right)$, and $C_{p}$ is the specific heat capacity of moist air $\left(\mathrm{J} \mathrm{kg}^{-1} \mathrm{~K}^{-1}\right)$. The estimated uncertainty of the aspirated thermocouple temperature measurement is $0.1^{\circ} \mathrm{C} . \delta \mathrm{C}_{\mathrm{a}}$ was estimated as the mean concentration multiplied by the overall method precision estimated as the non-parametric coefficient of variation (Sirois and Vet, 1999) of field duplicate measurements of the same compound using the same method (Table 2).

Error analysis applied to the bulk flux given by Eq. (1), which is applied here to both W2F and COARE flux calculations, yields:

$\frac{\delta F}{F}=\sqrt{\left(\frac{\delta k_{\mathrm{ol}}}{k_{\mathrm{ol}}}\right)^{2}+\left(\frac{k_{\mathrm{ol}} C_{\mathrm{a}} R T_{\mathrm{w}}}{F H} \frac{\delta H}{H}\right)^{2}+\left(\frac{k_{\mathrm{ol}} R T_{\mathrm{w}}}{F H} \delta C_{\mathrm{a}}\right)^{2}+\left(\frac{k_{\mathrm{ol}}}{F} \delta C_{\mathrm{w}}\right)^{2}}$

A value of 0.3 for $\frac{\delta k_{01}}{k_{\text {ol }}}$ was selected after the error analysis of Hoff (1994), which also is a reasonable approximation of the range of measured $k_{\mathrm{ol}}$ for DMS in Blomquist et al. (2006, Fig. 1). The estimated relative error in $C_{\mathrm{a}}$ was taken from Table 2, and relative error in $C_{\mathrm{w}}$ was estimated as the relative standard deviation of the available aqueous concentration measurements (Table 3), with a minimum value of 0.2 applied if fewer than three measurements were available. A value of 0.5 was selected for relative error in Henry's law constant after Blanchard et al. (2008).

\subsubsection{Ancillary data}

Inputs for the IBLTE model include upstream, over-land air temperature, dewpoint temperature, PBT atmospheric concentration, and wind speed, as well as water surface temperature and aqueous PBT concentration. For the 15-, 30-, and
Table 2. Overall method precision, expressed as the non-parametric coefficient of variation $(\mathrm{CoV})$ of field duplicates, using the same denuder sampling method as in the 14 July 2006 measurements (Rowe and Perlinger, 2009a).

\begin{tabular}{lcc}
\hline Compound & CoV & Number of duplicate pairs \\
\hline HCB & 0.09 & 5 \\
PCB 8 & 0.12 & 3 \\
PCB 18 & 0.12 & 5 \\
PCB 22 & 0.08 & 4 \\
PCB 28 & 0.04 & 4 \\
PCB 34 & $0.07^{\mathrm{a}}$ & 1 \\
PCB 110 & 0.10 & 4 \\
\hline
\end{tabular}

${ }^{a}$ Only one duplicate pair was available, so relative difference is reported.

Table 3. PBT concentration $\left(\mathrm{pg} \mathrm{L}^{-1}\right)$ in filtered Lake Superior water measured by Simcik et al. (2010) in July 2006. Mean, relative standard deviation (RSD), and number of measurements are reported.

\begin{tabular}{lccc}
\hline & Mean & RSD & Count \\
\hline HCB & 4.1 & 0.34 & 6 \\
PCB 8 & 3.4 & 0.26 & 7 \\
PCB 18 & 1.2 & 0.26 & 5 \\
PCB 28 & 3.8 & 0.36 & 2 \\
PCB 22 & 1.1 & 0.48 & 6 \\
PCB 110 & 2.0 & 0.32 & 6 \\
\hline
\end{tabular}

60-km stations, over land meteorological variables were averaged from meteorological stations at Sault Sainte Marie, Munising, and Newbury, MI. The time for the initial overland conditions was adjusted for travel time over water using the fetch and wind speed given in Table 1. Over-land air temperatures (and dewpoint temperatures) were $18.8^{\circ} \mathrm{C}$ $\left(16.5^{\circ} \mathrm{C}\right), 23.5^{\circ} \mathrm{C}\left(17.6^{\circ} \mathrm{C}\right)$, and $27.4^{\circ} \mathrm{C}\left(18.2^{\circ} \mathrm{C}\right)$; wind speed was $2.1,3.1$, and $3.7 \mathrm{~m} \mathrm{~s}^{-1}$, respectively. Water surface temperature as a function of fetch to each station was obtained by extracting the satellite-derived NOAA GLSEA lake surface temperature data product along the NOAA HYSPLIT model back trajectory.

Upstream, over-land atmospheric PBT concentration was estimated from values measured at $15-\mathrm{km}$ fetch. Volatilization fluxes were indicated for all PBTs, so the minimum concentration measured at the $15 \mathrm{~km}$ station was used as an estimate of the over-land concentration for input to the IBLTE model. Aqueous PBT concentrations reported by Simcik et al. (2010, data provided by Eric Osantowski, US Environmental Protection Agency, 29 December 2010) for Lake Superior in July, 2006, are given in Table 3. Environment Canada measured HCB concentration in Lake Superior surface water in May and June of 2005, and found a mean concentration of $12.5 \mathrm{pg} \mathrm{L}^{-1}(n=14, \mathrm{RSD}=0.09$, data provided by Jasmine Waltho, Environment Canada, 30 September 


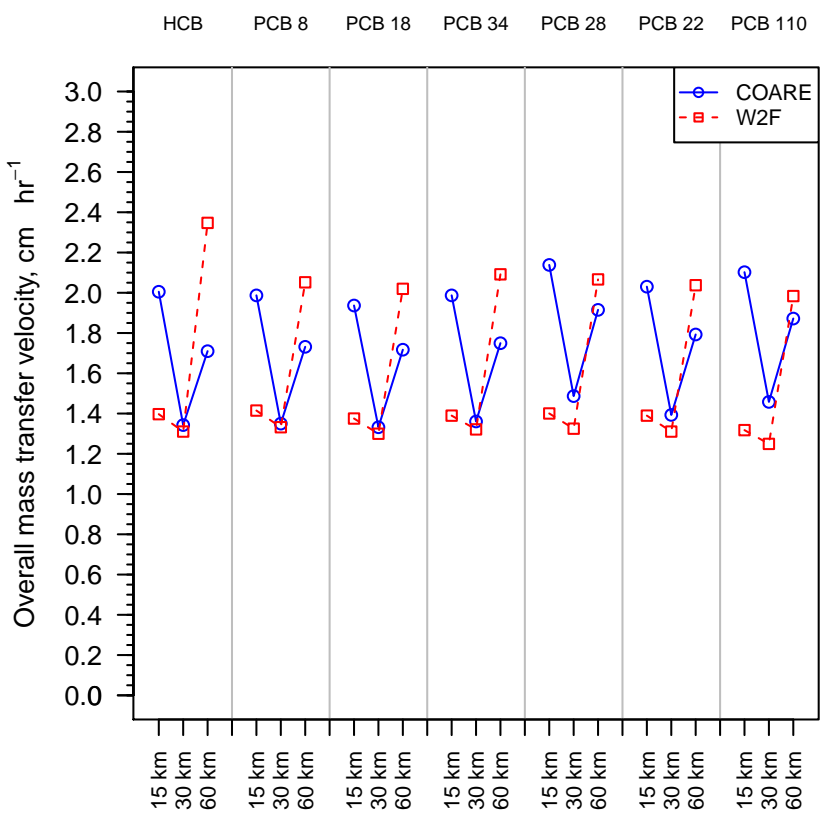

Fig. 2. Overall mass transfer velocity, kol, for each PBT at the 15, 30 , and $60 \mathrm{~km}$ stations.

2009), which is about three times greater than the value reported by Simcik et al.

\section{Results and discussion}

To investigate whether or not fluxes measured at the upper platform are representative of the surface flux, sensible heat flux measured by EC was compared to sensible heat flux estimated by the COARE algorithm using meteorological data in Table 1. EC and COARE sensible heat flux agreed within the estimated measurement uncertainty at the three stations. Fairall et al. (2006) found that EC fluxes of momentum, sensible heat, and latent heat were biased low compared to COARE fluxes when the measurement height was greater than about $10 \%$ of the internal boundary layer height in coastal offshore flow under stable conditions. Agreement between EC and COARE sensible heat flux suggests that fluxes measured at $8.5 \mathrm{~m}$ were reasonably representative of surface fluxes.

The influence of gas transfer model selection on $k_{\mathrm{ol}}$ was considered by calculating $k_{\mathrm{ol}}$ for each compound using the meteorological conditions at each station and the two gas transfer models (Fig. 2). The COARE model gave higher $k_{\mathrm{ol}}$ than the W2F model at the $15-\mathrm{km}$ station where water and air temperatures were equal. Stability increased with fetch at the three stations such that the COARE model gave similar, then lower, $k_{\mathrm{ol}}$ at the 30 - and $60-\mathrm{km}$ stations, respectively. The difference in $k_{\mathrm{ol}}$ between the two models, relative to the average $k_{\mathrm{ol}}$ of the two models, was up to $53 \%$ for the conditions considered here.

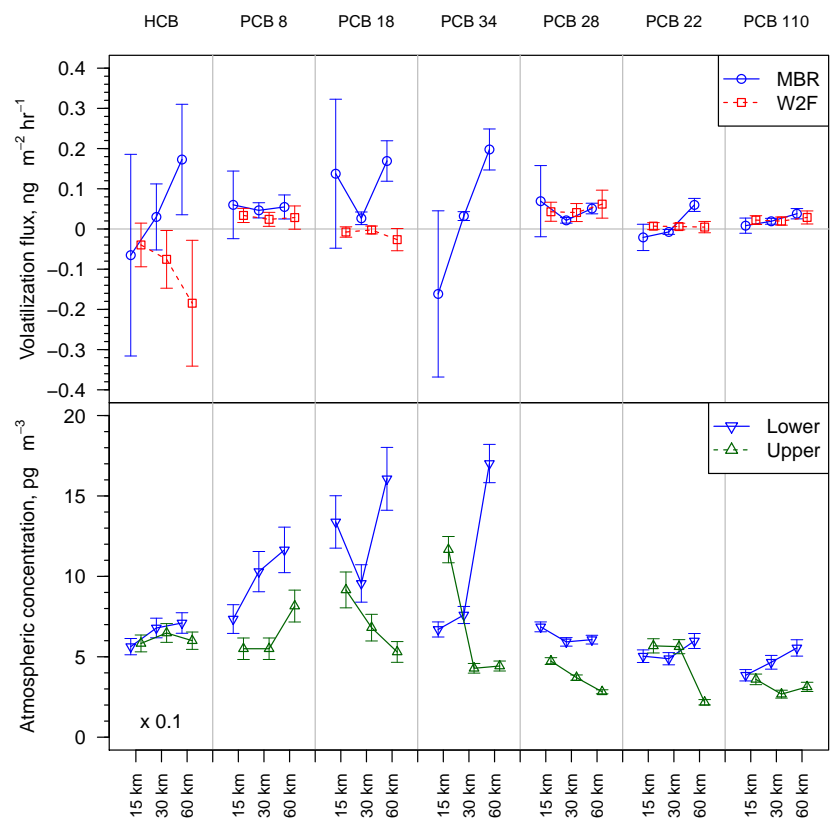

Fig. 3. Comparison of modified Bowen ratio and Whitman two-film fluxes to atmospheric concentrations measured at the upper $(8.5 \mathrm{~m})$ and lower ( $1 \mathrm{~m}$ ) platforms at the 15-, 30-, and 60-km fetch stations. MBR and W2F fluxes are plotted in the upper panel, both with estimated uncertainty given by the error bar. The atmospheric concentrations are plotted in the lower panel, with error bars indicating the uncertainty estimates in Table 2 . Note that the HCB concentration was divided by ten to put it on the same scale as the other concentrations. In five of seven cases for which a significant non-zero MBR flux was measured, concentration increased significantly with fetch at $1-\mathrm{m}$ height between the 15 and $60 \mathrm{~km}$ stations, with the exception of PCB 28.

PBT concentrations measured at 1-m and 8.5-m height at the 15-, 30-, and 60-km stations are presented in Table 4 and Fig. 3. In five of seven cases in which the MBR flux was significantly greater than zero, concentration increased with fetch at 1-m height, which is consistent with the measured volatilization flux.

Atmospheric concentration decreased over the course of the day at the upper platform for all PCBs except PCB 8, in apparent contradiction to indications of volatilization flux from the lake. This may be caused by a reduction in concentration over the course of the day in the mixed-layer air incident at the coast. Diel variation in atmospheric PCB concentration has been observed and attributed to reaction with hydroxyl radical $(\mathrm{OH})$ and/or dilution by growth of the atmospheric mixed layer over the day (Mandalakis et al., 2003; MacLeod et al., 2007; Totten et al., 2002).

Reduction in concentration at $8.5-\mathrm{m}$ height increased with increasing reaction rate constant with $\mathrm{OH}$ (Fig. 4), suggesting that reaction with $\mathrm{OH}$ may have caused a reduction in $\mathrm{PCB}$ concentration incident at the coast over the course of the day. PCB 8 was an exception to this trend, however, the 60- to 
Table 4. Atmospheric PBT concentration measured at the upper (8.5-m) and lower (1-m) platforms at 15-, 30-, and 60-km stations in Lake Superior, 14 July $2006\left(\mathrm{pg} \mathrm{m}^{-3}\right.$ at $\left.25^{\circ} \mathrm{C}, 1 \mathrm{~atm}\right)$.

\begin{tabular}{lcccc}
\hline & Height, $\mathrm{m}$ & $15 \mathrm{~km}$ & $30 \mathrm{~km}$ & $60 \mathrm{~km}$ \\
\hline HCB & 8.5 & 58.3 & 64.8 & 60.0 \\
& 1 & 56.3 & 67.9 & 71.0 \\
PCB 8 & 8.5 & $<5.5$ & $<5.5$ & 8.2 \\
& 1 & 7.3 & 10.3 & 11.6 \\
PCB 18 & 8.5 & 9.2 & 6.8 & $<5.3$ \\
& 1 & 13.4 & 9.6 & 16.1 \\
PCB 34 & 8.5 & 11.7 & 4.3 & 4.4 \\
& 1 & 6.7 & 7.6 & 17.0 \\
PCB 28 & 8.5 & 4.7 & 3.7 & 2.8 \\
& 1 & 6.9 & 5.9 & 6.1 \\
PCB 22 & 8.5 & 5.7 & 5.6 & 2.2 \\
& 1 & 5.0 & 4.9 & 6.0 \\
PCB 110 & 8.5 & 3.6 & 2.7 & 3.1 \\
& 1 & 3.8 & 4.7 & 5.6 \\
\hline
\end{tabular}

a " $<$ " indicates the value measured was less than the method detection limit (MDL); the value reported is the MDL value.

$15-\mathrm{km}$ concentration ratio for this compound may be high due to the measurement of a $15-\mathrm{km}$ concentration less than the method detection limit (Table 4). Also shown in Fig. 4 is the calculated reduction in concentration due to destruction by $\mathrm{OH}$, assuming a typical daytime, mid-latitude, continental $\mathrm{OH}$ concentration of 1 to $7 \times 10^{6}$ molecules $\mathrm{cm}^{-3}$ (Thompson, 1995). The difference between the estimates of concentration indicated by the dashed lines and the measurements in Fig. 4 indicate that it is unlikely that destruction by $\mathrm{OH}$ over the 7-h sampling time period can fully account for the observed reduction in concentration.

As an alternative but related mechanism, compounds with greater hydroxyl radical reactivity may have lesser mean mixing ratio in the upper boundary layer and lower free troposphere than near the surface, resulting in dilution as the mixed layer increased in height over the day. A correlation between the reduction in mixing ratio with height in the atmosphere and $\mathrm{OH}$ reactivity is expected because sources of organic compounds are near the surface while destruction by $\mathrm{OH}$ occurs throughout the volume, and such a correlation has been observed for a variety of organic compounds (Anderson and Hites, 1996). Few measurements of PBT mixing ratio at multiple heights above the surface have been reported, but Anderson and Hites estimated average atmospheric vertical gradient for tri-chloro PCBs by analogy to propane, which has similar $\mathrm{OH}$ reactivity. According to their estimate, the ratio of tri-chloro $\mathrm{PCB}$ mixing ratio at $2 \mathrm{~km}$ to that at the surface is about 0.73 . This suggests that a reduction in PBT mixing ratio at the surface due to dilution, but correlated to $\mathrm{OH}$ reactivity, may occur as the mixed layer grows during the day. Neither of these phenomenon alone $(\mathrm{OH}$ reaction, dilution) appears large enough to account for the reduction

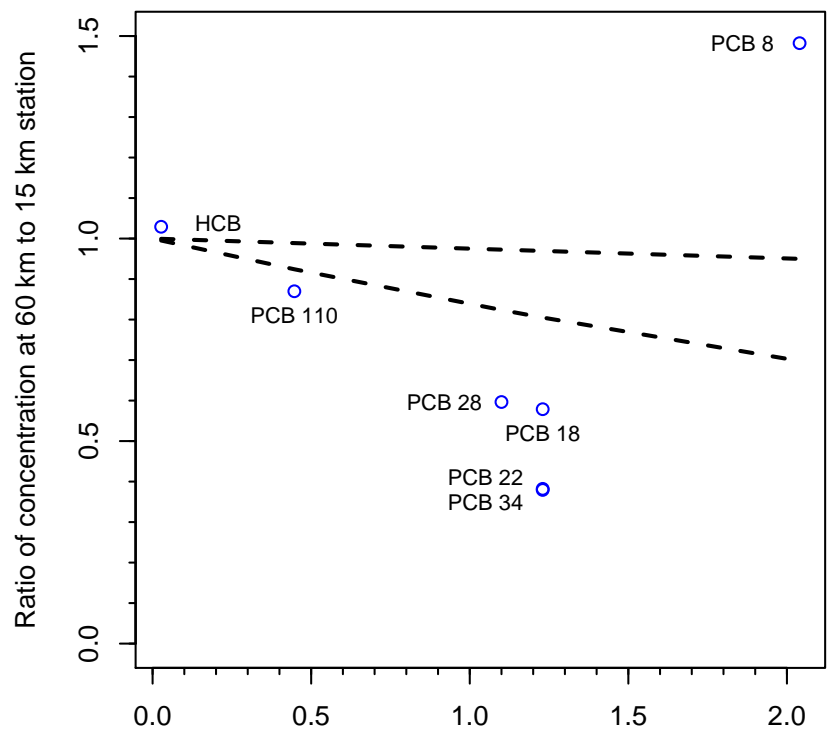

$\mathrm{OH}$ reaction rate constant, $298 \mathrm{~K}, 10^{-12} \mathrm{~cm}^{3}$ molecule $\mathrm{s}^{-1}$

Fig. 4. Ratio of $60-\mathrm{km}$ station to $15-\mathrm{km}$ station $(13: 18-14: 48$ to 06:20-07:50 local time) PBT concentration at $8.5 \mathrm{~m}$ height versus hydroxyl radical reaction rate constant for PBTs in air over Lake Superior on 14 July 2006 (symbols). The calculated reduction in concentration by $\mathrm{OH}$-radical reaction over a 7-h period is shown by the dashed lines for a typical range in daytime, mid-latitude, continental $\mathrm{OH}$ concentration of $1 \times 10^{6}$ (upper line) to $7 \times 10^{6}$ molecules $\mathrm{cm}^{-3}$ (lower line).

factor of 0.6 shown in Fig. 4 for tri-chloro PCBs, but perhaps a combination of dilution and reaction may have caused the reduction.

Measured and predicted fluxes are shown in Fig. 3. COARE fluxes (not shown) fell within the estimated uncertainty range of the W2F fluxes because they rely on the same $C_{\mathrm{w}}$ and $H$. All W2F fluxes that were significantly different from zero were positive (volatilization), which is consistent with the increase in concentration with fetch at 1-m height observed for five of seven compounds. Volatilization fluxes may be expected for these compounds during the summer when Lake Superior surface water is near its warmest point in the annual cycle.

Uncertainty estimates shown in the error bars of Fig. 3 are useful to distinguish the conditions under which MBR flux measurements were significantly different from zero, and to indicate whether or not differences between MBR and W2F fluxes are significant relative to the uncertainty. Contributions of the individual terms in Eqs. (13) and (14) to the overall relative error are given in Tables S1 and S2 of the Supplement. At the 30 - and $60-\mathrm{km}$ stations, the MBR flux is significantly greater than zero in 12 of 14 cases (Fig. 3). At the $15-\mathrm{km}$ station stability was near neutral, which resulted in small temperature and concentration gradients, as well as a small sensible heat flux, all of which contributed to a large 


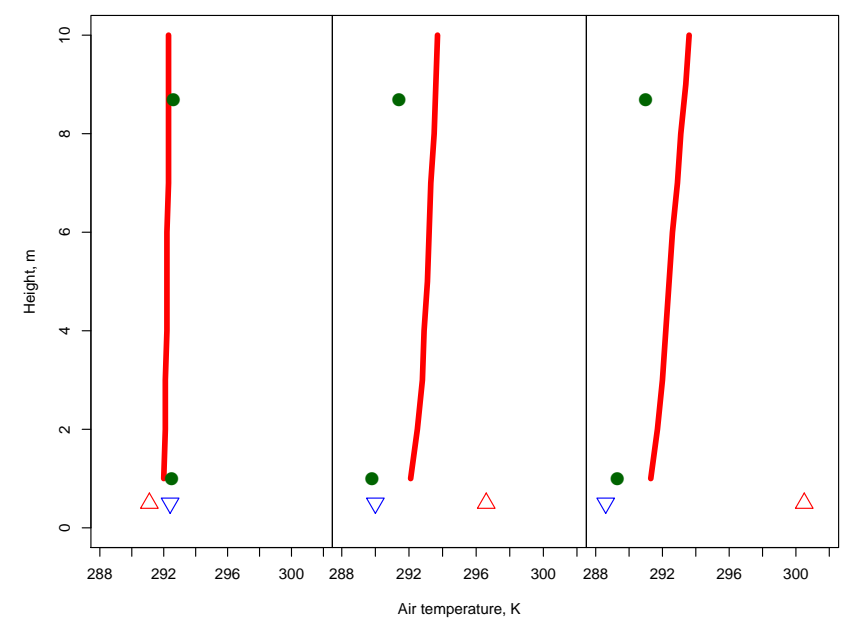

Fig. 5. Measured (circles) and IBLTE-modeled (line) air temperature at the 15-, 30-, and 60-km stations (panels from left to right). The water surface temperature is plotted as a downward-pointing blue triangle, and the initial over-land air temperature as an upwardpointing red triangle.

relative error in the MBR measurement at $15 \mathrm{~km}$. At 30 and $60 \mathrm{~km}$, the air temperature had increased over the course of the day and water temperature decreased with fetch (Fig. 1), which enhanced atmospheric stability, temperature gradient, sensible heat flux, and PBT gradient with fetch, conditions favorable for measurement of the flux using the MBR technique. At 15 and $30 \mathrm{~km}$, measurement of the small PBT or temperature gradient was the greatest single contribution to uncertainty. At $60 \mathrm{~km}$, gradients had become large enough, and sensible heat flux small enough, that the heat flux measurement contributed most to overall uncertainty. The relative errors for W2F flux measurements may be considered rough estimates because the uncertainty in $k_{\mathrm{ol}}$ and $H$ are estimated, and few $C_{\mathrm{w}}$ measurements were available from which to estimate spatial, temporal, and measurement variability in $C_{\mathrm{w}}$. Uncertainty in $C_{\mathrm{w}}$ was the greatest single contribution to relative error in the $\mathrm{W} 2 \mathrm{~F}$ flux estimate in most cases, and may be underestimated in Table S2 due to the small number of available $C_{\mathrm{w}}$ measurements. The contribution of uncertainty in $H$ varied from small to large, depending on how close $C_{\mathrm{a}}$ was to equilibrium with $C_{\mathrm{w}}$. The error analysis indicates that uncertainty in flux measurements could be reduced in future work through use of replicate concentration measurements at each platform, and through use of a second scalar in addition to potential temperature, such as water vapor, to quantify atmospheric transfer velocity in the MBR method.

The IBLTE model was applied to compare modeled to measured flux, modification in concentration, and vertical gradients in concentration near the surface. Modeled and measured modification in air temperature and specific humidity, and vertical gradient in air temperature, were in reasonable agreement, although modification was over-

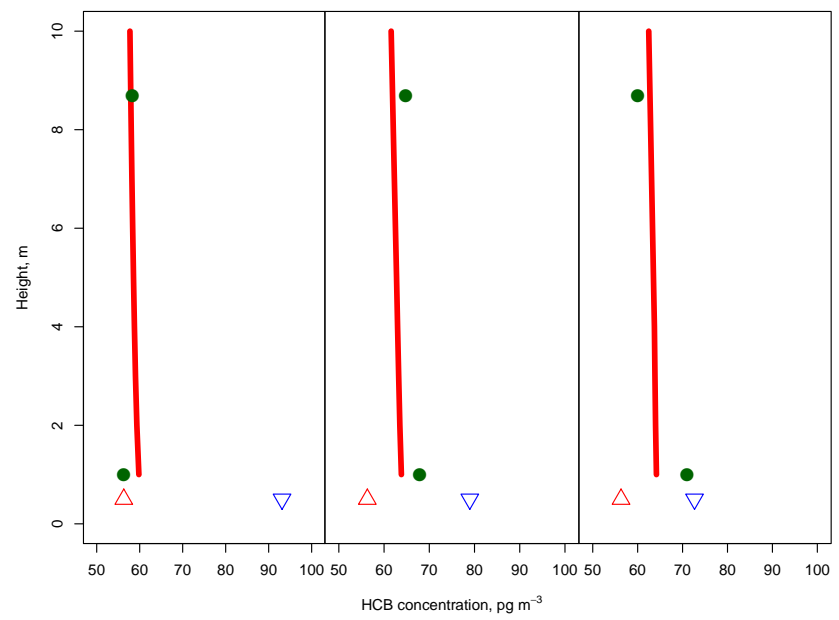

Fig. 6. Measured (circles) and IBLTE modeled (line) HCB atmospheric concentration at the 15-, 30-, and 60-km stations (panels from left to right). The HCB concentration at equilibrium with the water surface is plotted as a downward-pointing blue triangle, and the initial over-land HCB concentration as an upward-pointing red triangle. An increase in $\mathrm{HCB}$ atmospheric concentration with fetch was observed at 1-m height, consistent with model prediction based on the aqueous HCB concentration of Environment Canada, but not with the lower aqueous concentration of Simcik et al. (2010). The Environment Canada concentration was used in this figure.

estimated (Fig. 5); this result provides a means to evaluate the treatment of vertical mixing in the atmosphere by the IBLTE model. Use of the lower HCB aqueous concentration reported by Simcik et al. (2010) caused the IBLTE model to predict modification of atmospheric HCB with fetch in the opposite direction of what was observed. In contrast, use of the higher aqueous HCB concentration reported by Environment Canada caused the IBLTE model to predict modification of atmospheric HCB concentration with fetch that was in reasonable agreement with observation (Fig. 6). This is an example of how the model can be applied to reveal inconsistencies in these challenging measurements of trace concentrations and fluxes of PBTs.

\section{Conclusions}

Measurement and estimation of air-water exchange fluxes of organic toxics that are present at $\mathrm{pg} \mathrm{m}^{-3}$ concentrations in the atmosphere and at $\mathrm{pg} \mathrm{L}^{-1}$ aqueous concentrations is challenging because several measurements, each of which may have considerable uncertainty, must be combined. Here, a transect measurement approach that incorporates modified Bowen ratio flux measurements collected at stations with increasing fetch in offshore flow was combined with an internal boundary layer transport exchange model to provide an opportunity for critical evaluation of measured and estimated fluxes by quantitative comparison of measured and modeled 
modification in PBT atmospheric concentration with fetch at 1 -m height over the water. Significantly non-zero volatilization fluxes were measured by the MBR method for HCB and several PCB congeners. Volatilization fluxes were consistent with observed increase in concentration with fetch at 1-m height for most compounds.

Improvements in chemical concentration measurement precision allowed us to report ship-based micrometeorological measurements of PCB air-water exchange fluxes for the first time here. Even so, further improvement in flux measurement precision is needed to critically compare the accuracy of the COARE gas transfer model to the Whitman two-film model. Estimates of transfer velocity from the two gas transfer models differed by up to $53 \%$ for the conditions encountered. Error analysis indicates that uncertainty in flux measurements could be reduced in future work through use of replicate concentration measurements at each platform, and by use of a second scalar, such as water vapor, to quantify atmospheric transfer velocity in the MBR method.

\section{Supplementary material related to this article is available online at: http://www.atmos-chem-phys.net/12/ 4607/2012/acp-12-4607-2012-supplement.pdf.}

Acknowledgements. Funding for this research was provided through a grant from the Great Lakes Commission. A scholarship to M. D. Rowe through NSF Grant \#DUE-0806569 provided partial support for participation. We thank the captain and crew of US EPA R/V Lake Guardian for collaboration in conducting field measurements. David Tobias participated in field work. Fritz Burt, Eric Bradfish, Shannon Flynn, and Kenny Papes assisted with calibration of instruments. Chris Fairall provided helpful discussions.

Edited by: J. Rinne

\section{References}

Anderson, P. N. and Hites, R. A.: OH radical reactions: the major removal pathway for polychlorinated biphenyls from the atmosphere, Environ. Sci. Technol., 30, 1756-1763, 1996.

Bamford, H., Poster, D., Huie, R., and Baker, J.: Using extrathermodynamic relationships to model the temperature dependence of Henry's Law constants of 209 PCB congeners, Environ. Sci. Technol., 36, 4395-4402, 2002.

Bidleman, T. and McConnell, L. L.: A review of field experiments to determine air-water gas exchange of persistent organic pollutants, Sci. Tot. Environ., 159, 101-117, 1995.

Blanchard, P., Audette, C. V., Hulting, M. L., Basu, I., Brice, K., Backus, S., Dryfhout-Clark, H., Froude, F., Hites, R., Nielson, M., and Wu, R.: Atmospheric Deposition of Toxic Substances to the Great Lakes: IADN Results through 2005, US EPA and Environment Canada, US EPA 905-R-08-001, 226, 2008.
Blomquist, B. W., Fairall, C. W., Huebert, B. J., Kieber, D. J., and Westby, G. R.: DMS sea-air transfer velocity: Direct measurement by eddy covariance and parameterization based on the NOAA/COARE gas transfer model, Geophys. Res. Lett., 33, 14, 2006.

Cetin, B. and Odabasi, M.: Measurement of Henry's law constants of seven polybrominated diphenyl ether (PBDE) congeners as a function of temperature, Atmos. Environ., 39, 5273-5280, 2005.

Dachs, J., Lohmann, R., Ockenden, W., Mejanelle, L., Eisenreich, S., and Jones, K.: Oceanic biogeochemical controls on global dynamics of persistent organic pollutants, Environ. Sci. Technol., 36, 4229-4237, 2002.

Edson, J. B., Hinton, A. A., Prada, K. E., Hare, J. E., and Fairall, C. W.: Direct covariance flux estimates from mobile platforms at sea, J. Atmos. Oceanic Technol., 15, 547-562, 1998.

Fairall, C. W., Hare, J. E., Edson, J. B., and McGillis, W.: Parameterization and micrometeorological measurement of air-sea gas transfer, Bound.-Lay. Meteorol., 96, 63-105, 2000.

Fairall, C. W., Bradley, E. F., Hare, J. E., Grachev, A. A., and Edson, J. B.: Bulk parameterization of air-sea fluxes: updates and verification for the COARE Algorithm, J. Clim., 16, 571-591, 2003.

Fairall, C. W., Bariteau, L., Grachev, A. A., Hill, R. J., Wolfe, D. E., Brewer, W. A., Tucker, S. C., Hare, J. E., and Angevine, W. M.: Turbulent bulk transfer coefficients and ozone deposition velocity in the International Consortium for Atmospheric Research into Transport and Transformation, J. Geophys. Res., 111, D23S20, doi:10.1029/2006JD007597, 2006.

Fuller, E. N., Schettler, P. D., and Giddings, J. C.: A new method for prediction of binary gas-phase diffusion coefficient, Ind. Eng. Chem., 58, 19-27, 1966.

Galarneau, E., Audette, C., Bandemehr, A., Basu, I., Bidleman, T. F., Brice, K. A., Burniston, D. A., Chan, C. H., Froude, F., Hites, R. A., Hulting, M. L., Neilson, M., Orr, D., Simcik, M. F., Strachan, W. M. J., and Hoff, R. M.: Atmospheric deposition of toxic substances to the Great Lakes: IADN results to 1996, Environment Canada, US EPA, Toronto, ON, Canada, EPA 905R-00004, 126, 2000.

Gioia, R., Nizzetto, L., Lohmann, R., Dachs, J., Temme, C., and Jones, K.: Polychlorinated biphenyls (PCBs) in air and seawater of the atlantic ocean: sources, trends and processes, Environ. Sci. Technol., 42, 1416-1422, 2008.

Gioia, R., Jones, K. C., Lohmann, R., Nizzetto, L., and Dachs, J.: Field-derived Henry's law constants for polychlorinated biphenyls in oceanic waters, J. Geophys. Res., 115, C05024, doi:10.1029/2008JC005054, 2010.

Hare, J. E., Fairall, C. W., McGillis, W. R., Edson, J. B., Ward, B., and Wanninkhof, R.: Evaluation of the NOAA/COARE airsea gas transfer parameterization using GasEx data, J. Geophys. Res., 109, C08S11, doi:10.1029/2003JC001831, 2004.

Harman-Fetcho, J., McConnell, L., Rice, C., and Baker, J.: Wet deposition and air-water gas exchange of currently used pesticides to a subestuary of the Chesapeake Bay, Environ. Sci. Technol., 34, 1462-1468, 2000.

Ho, D. T., Law, C. S., Smith, M. J., Schlosser, P., Harvey, M., and Hill, P.: Measurements of air-sea gas exchange at high wind speeds in the Southern Ocean: Implications for global parameterizations, Geophysical Research Letters, 33, 16, doi:10.1029/2006GL026817, 2006. 
Hoff, R. M.: An error budget for the determination of the atmospheric mass loading of toxic chemicals in the Great Lakes, J. Great Lakes Res., 20, 229-239, 1994.

Hornbuckle, K. C., Jeremiason, J. D., Sweet, C. W., and Eisenreich, S. J.: Seasonal variations in air-water exchange of polychlorinated biphenyls in Lake Superior, Environ. Sci. Technol., 28, 1491-1501, 1994.

Jantunen, L. M. and Bidleman, T. F.: Temperature dependent Henry's law constants for hexachlorobenzene, p,p'-DDE, and components of technical chlordane and estimates of gas exchange in Lake Ontario, Chemosphere, 62, 1689-1696, 2006.

Jeremiason, J. D., Hornbuckle, K. C., and Eisenreich, S. J.: PCBs in Lake Superior, 1978-1992: Decreases in water concentrations reflect loss by volatilization., Environ. Sci. Technol., 28, 903914, 1994.

Mackay, D. and Yeun, A.: Mass transfer coefficient correlations for volatilization of oranic solutes from water, Environ. Sci. Technol., 17, 211-217, 1983.

MacLeod, M., Scheringer, M., Podey, H., Jones, K., and Hungerbuhler, K.: The origin and significance of short-term variability of semivolatile contaminants in air, Environ. Sci. Technol., 41, 3249-3253, 2007.

Mandalakis, M., Berresheim, H., and Stephanou, E. G.: Direct evidence for destruction of polychlorobiphenyls by $\mathrm{OH}$ radicals in the subtropical troposphere, Environ. Sci. Technol., 37, 542-547, 2003.

Marandino, C., De Bruyn, W., Miller, S., and Saltzman, E.: Open ocean DMS air/sea fluxes over the eastern South Pacific Ocean, Atmos. Chem. Phys., 9, 345-356, doi:10.5194/acp-9-345-2009, 2009.

Meng, F., Wen, D., and Sloan, J.: Modelling of air-water exchange of PCBs in the Great Lakes, Atmos. Environ., 42, 4822-4835, 2008.

Perlinger, J. A., Tobias, D. E., Morrow, P. S., and Doskey, P. V.: Evaluation of novel techniques for measurement of air-water exchange of persistent bioaccumulative toxicants in Lake Superior, Environ. Sci. Technol., 39, 8411-8419, 2005.

Rowe, A., Totten, L., Xie, M., Fikslin, T., and Eisenreich, S.: Airwater exchange of polychlorinated biphenyls in the Deleware River, Environ. Sci. Technol., 41, 1152-1158, 2007.

Rowe, M. D. and Perlinger, J. A.: Gas-phase cleanup method for analysis of trace atmospheric semivolatile organic compounds by thermal desorption from diffusion denuders, J. Chromatogr. A, 1216, 5940-5948, doi:10.1016/j.chroma.2009.06.034, 2009a.

Rowe, M. D. and Perlinger, J. A.: Prediction of gas collection efficiency and particle collection artifact for atmospheric semivolatile organic compounds in multicapillary denuders, J. Chromatogr. A, 1217, 256-263, doi:10.1016/j.chroma.2009.11.049, 2009b.

Rowe, M. D., Perlinger, J. A., and Fairall, C. W.: A Lagrangian Model to Predict the Modification of Near-Surface Scalar Mixing Ratios and Air-Water Exchange Fluxes in Offshore Flow, Bound.-Lay. Meteorol., 140, 87-103, doi:10.1007/s10546-0119598-0, 2011a.

Rowe, M. D., Fairall, C. W., and Perlinger, J. A.: Chemical sensor resolution requirements for near-surface measurements of turbulent fluxes, Atmos. Chem. Phys, 11, 5263-5275, doi:10.5194/acp-11-5263-2011, 2011b.
Rowe, M. D., Perlinger, J. A., and Urban, N. R.: Modeling contaminant behavior in Lake Superior: A comparison of PCBs, PBDEs, and mercury, in: State of Lake Superior, Ecovision World Monograph Series, edited by: Munawar, M., and Munawar, I. F., Aquat. Ecosyst. Health Manage. Soc., Burlington, Canada, 2008.

Sandy, A. L., Guo, J., Miskewitz, R. J., McGillis, W. R., and Rodenburg, L. A.: Fluxes of polychlorinated biphenyls volatilizing from the Hudson River, New York measured using micrometeorological approaches, Environ. Sci. Technol., 46, 885-891, doi:10.1021/es203446w, 2012.

Schwarzenbach, R. P., Gschwend, P. M., and Imboden, D. M.: Environmental Organic Chemistry, 2nd ed., Wiley Interscience, New York, USA, 681 pp., 2003.

Simcik, M. F.: Great Lakes Aquatic Contaminants Survey - Final Report, US Environmental Protection Agency, Great Lakes National Programs Office, Grant GL GL96512301, 2010.

Sirois, A. and Vet, R.: The precision of precipitation chemistry measurements in the Canadian air and precipitation monitoring network (CAPMON), Environ. Monit. Assess., 57, 301-329, 1999.

Thompson, A.: Measuring and modeling the tropospheric hydroxyl radical (OH), J. Atmos. Sci., 52, 3315-3327, 1995.

Tobias, D. E., Perlinger, J. A., Morrow, P. S., Doskey, P. V., and Perram, D. L.: Direct thermal desorption of semivolatile organic compounds from diffusion denuders and gas chromatographic analysis for trace concentration measurement, J. Chromatogr. A, 1140, 1-12, 2007.

Totten, L., Brunciak, P., Gigliotti, C., Dachs, J., Glenn IV, T., Nelson, E., and Eisenreich, S.: Dynamic air-water exchange of polychlorinated biphenyls in the New York-New Jersey Harbor estuary, Environ. Sci. Technol., 35, 3834-3840, 2001.

Totten, L. A., Eisenreich, S. J., and Brunciak, P. A.: Evidence for destruction of $\mathrm{PCBs}$ by the $\mathrm{OH}$ radical in urban atmospheres, Chemosphere, 47, 735-746, 2002.

US EPA: National Listing of Fish Advisories, http://water.epa.gov/ scitech/swguidance/fishshellfish/fishadvisories/index.cfm last access: 15 August 2009, 2008.

Wanninkhof, R., Ledwell, J. R., and Crusius, J.: in: Air-Water Mass Transfer, edited by: Wilhelm, S. C., and Gulliver, J. S., American Society of Civil Engineers, New York, USA, 441-458, 1991.

Wesely, M. L., Lenschow, D. H., and Denmead, O. T.: Flux measurement techniques, in: Global Tropospheric Chemistry: Chemical Fluxes in the Global Atmosphere, Measurements of surface exchange and flux divergence of chemical species in the global atmosphere, Columbia University, 31-45, 1987.

White, F. M.: Fluid Mechanics, 4 ed., McGraw-Hill, New York, USA, 1999.

Wong, F., Jantunen, L. M., Pucìko, M., Papakyriakou, T., Staebler, R. M., Stern, G. A., and Bidleman, T. F.: Air-Water Exchange of Anthropogenic and Natural Organohalogens on International Polar Year (IPY) Expeditions in the Canadian Arctic, Environ. Sci. Technol., 45, 876-881, doi:10.1021/es1018509, 2011.

Yan, S., Rodenburg, L., Dachs, J., and Eisenreich, S.: Seasonal airwater exchange fluxes of polychlorinated biphenyls in the Hudson River Estuary, Environ. Pollut., 152, 443-451, 2008.

Zhang, X., Rygwelski, K., Rossman, R., Pauer, J., and Kreis Jr., R.: Model construct and calibration of an integrated water quality model (LM2-Toxic) for the Lake Michigan Mass Balance Project, Ecol. Model., 219, 92-106, 2008. 